\title{
Concomitant Characterization of Behavioral and Striatal Neurotransmitter Response to Amphetamine Using in vivo Microdialysis
}

\author{
Ronald Kuczenski and David Segal \\ Department of Psychiatry, University of California, San Diego, La Jolla, California 92093
}

The temporal and dose-related behavioral and striatal monoamine response to amphetamine (AMPH) was examined using in vivo microdialysis in freely moving rats. Extracellular dopamine (DA), serotonin (5-HT), and their metabolites were monitored concomitant with detailed characterization of the locomotor and stereotypy profiles. Consistent with previous results, AMPH (0.5-5.0 $\mathrm{mg} / \mathrm{kg}$ ) induced a rapid dose-dependent increase in DA concentration and decrease in the concentrations of the DA metabolites, DOPAC and HVA. DA and its metabolites exhibited contrasting temporal and dose-related patterns, suggesting that the decline in DA metabolites is functionally dissociated from the AMPH-enhanced DA release. In addition, AMPH at doses of $2.0 \mathrm{mg} / \mathrm{kg}$ and greater significantly increased extracellular concentrations of 5-HT, which, in contrast to the changes in dopamine, persisted for only 20-40 min. Comparisons of concentrations of DA and 5-HT for individual animals revealed significant correlations both during baseline and drug response, suggesting a possible functional interdependence between dopaminergic and serotonergic activity in striatum.

Dose-response comparisons revealed a significant relationship between AMPH-induced increases in behavioral perseveration and the magnitude and duration of the DA release. However, the temporal patterns of the neurotransmitter response and individual components of stereotypy were not parallel, suggesting that the presence of stereotypies is not associated simply with quantitative differences in striatal DA release. By contrast, some features of the behavioral response were significantly correlated with AMPHinduced changes in striatal 5-HT concentrations. Our results suggest that the behavioral response to AMPH may be influenced by the interaction between levels of DA and 5-HT release, as well as by the state of their respective receptors.

Most efforts to define the biochemical mechanisms underlying the behavioral response to stimulants like amphetamine (AMPH) have been directed primarily at dopamine (DA) pathways. Converging evidence implicates the nigrostriatal DA pathway in some forms of the drug-induced stereotyped behaviors (Creese and Iversen, 1974; Kelly et al., 1975; Kelly, 1977), whereas the

\footnotetext{
Received Sept. 15, 1988; revised Nov. 9, 1988; accepted Nov. 11, 1988.

This work was supported by U.S. Public Health Service Grants DA-04157 and DA-01568 and by a Research Scientist Award MH-70183 to D.S.

Correspondence should be addressed to Ronald Kuczenski, Ph.D., Department of Psychiatry, M-003, University of California, San Diego, La Jolla, CA 92093.

Copyright (C) 1989 Society for Neuroscience $0270-6474 / 89 / 062051-15 \$ 02.00 / 0$
}

ventral tegmental DA system (mesolimbic and mesocortical pathways) appears to play a role in stimulant-induced locomotor activity (Kelly and Iversen, 1976; Sessions et al., 1980; Kehne et al., 1981; Swerdlow et al., 1986). In addition, other neurotransmitters may also modulate the AMPH response. For example, electrophysiological (Foote et al., 1969; Gallager and Aghajanian, 1976; Baraban et al., 1978), cytofluorometric (Geyer et al., 1975), and biochemical (Kuczenski et al., 1987) data suggest that AMPH affects serotonin (5-HT) neurotransmission, and some evidence indicates that manipulation of 5-HT function alters AMPH-induced locomotor activity (Neill et al., 1972; Mabry and Campbell, 1973; Breese et al., 1974; Costall and Naylor, 1974) and stereotypies (Segal, 1976; Sloviter et al., 1978; Lucki and Harvey, 1979).

However, although it is apparent that these monoamines are involved in the AMPH response, progress in establishing more precise neurochemical/behavioral relationships has been limited. This lack of success may derive, in part, because most biochemical characterizations of the presynaptic response to AMPH have utilized post-mortem measures of neurotransmitter metabolism. Interpretation of these indirect indices is further complicated by the multiple sites at which AMPH is alleged to alter neurotransmitter function (Kuczenski, 1983). In addition, whereas drug-induced behavioral and biochemical changes are dynamic and multiphasic, post-mortem measures are static with respect to the temporal features of the response. Furthermore, because biochemical data for each animal are limited to a single time point, determination of drug effects requires comparisons to nondrugged "control" animals. Between-animal comparisons may obscure important effects since, as we and others have found, there appears to be a wide range of individual differences in responsiveness to AMPH, as reflected in both the temporal and qualitative features of the response (Segal and Kuczenski, 1987a). Thus, potentially important insight into the contribution of specific neuronal systems to the behavioral response profile might be gained by the use of animals as their own controls through direct and continuous in vivo measures of synaptic transmitter levels in animals whose behavior is concomitantly monitored. The results of recent studies with psychostimulants such as AMPH and cocaine (Imperato and Di Chiara, 1985; Sharp et al., 1986, 1987; Westerink et al., 1987; Imperato et al., 1988) have demonstrated the feasibility of the intracerebral microdialysis technique to approach this objective. However, although those data confirm the profound influence of stimulants on dopaminergic function, a relationship between AMPH-induced changes in transmitter release and the behavioral response is less clear, particularly with regard to the role 
Figure 1. Left, Schematic of behavioral activity chamber, located within a sound-proofed cabinet. Dialysis samples are collected outside of the chamber, remote from the experimental animal. Right, The dialysis probe, $250 \mu \mathrm{m}$ tip diameter, is attached to the awake animal via a permanently implanted stainless steel guide cannula.
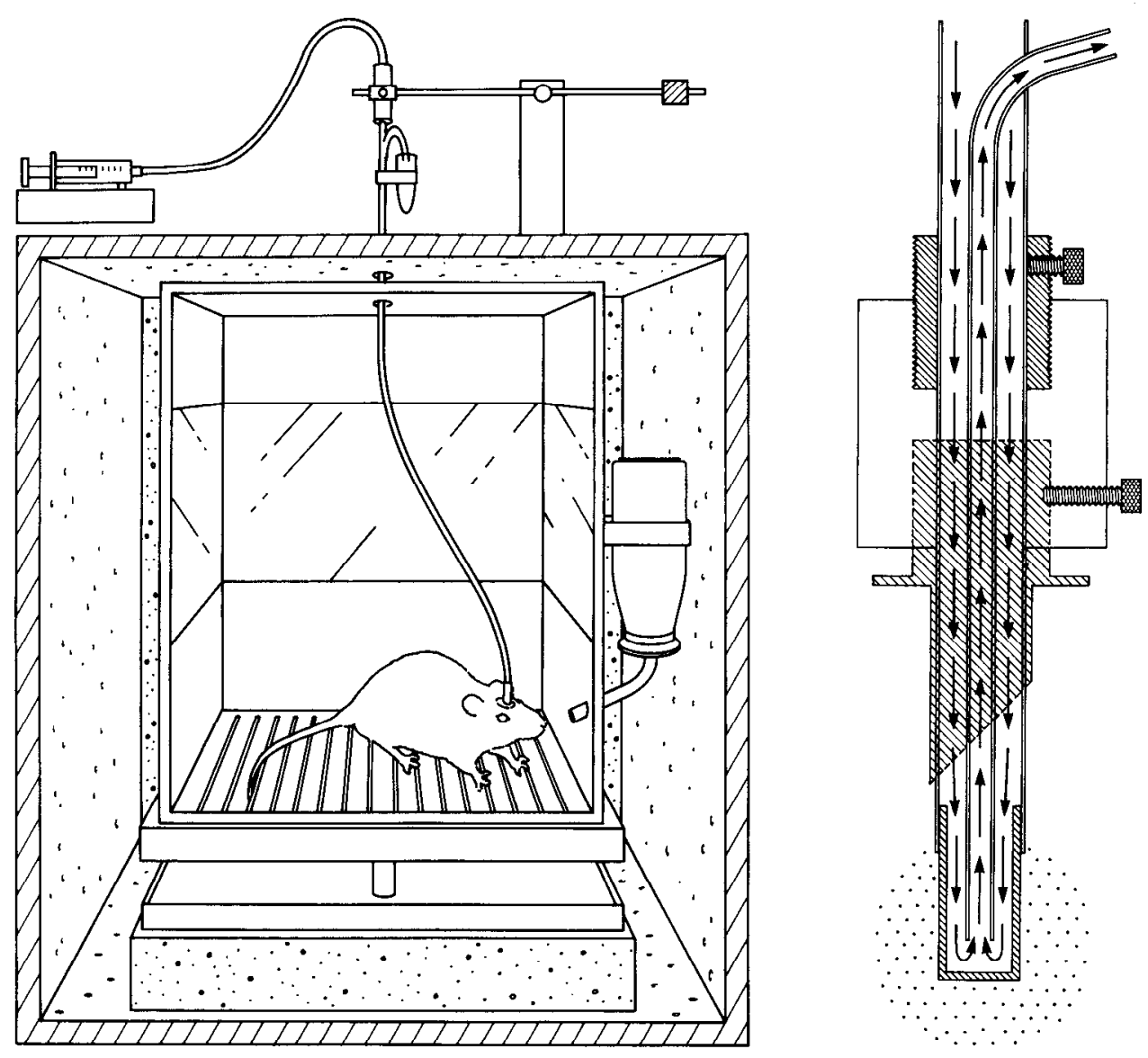

of striatal DA in the regulation of stereotyped behaviors (Westerink et al., 1987; Sharp et al., 1987).

The present study was designed to examine more systematically the temporal and dose-related response of striatal DA and 5-HT to AMPH concomitant with detailed characterization of the behavioral profiles. For these studies, we developed a removable dialysis probe that minimizes potential confounding of the drug response by recent anesthesia and surgery. In addition, we collected samples remote from the animal to eliminate the frequent disruption of the behavioral response associated with harness devices. Our results confirm and extend the previously described quantitative and qualitative features of the striatal dopamincrgic response to AMPH and further definc AMPH-induced changes in 5-HT function. In addition, the data suggest a dissociation between the temporal and dose-related features of the biochemical and behavioral response profiles.

\section{Materials and Methods}

Animals. Male Sprague-Dawley rats weighing 300-325 gm (Simonsen Labs.) were housed in constant-temperature/humidity animal facilities with continuous access to food and water. Animals were maintained under a reverse $12 \mathrm{hr}$ red light (6:00 AM-6:00 PM), $12 \mathrm{hr}$ white light cycle for at least a week prior to surgery. Each animal was anesthetized with halothane, placed in a stereotaxic device, and implanted, on either the right or left side of the skull, with a stainless steel guide cannula extending $2.6 \mathrm{~mm}$ below the surface of the skull. The patency of the cannula was maintained with a stainless steel stylet that projected 0.1 $\mathrm{mm}$ below the tip of the cannula. Following surgery, animals were allowed to recover for at least a week prior to further experimental manipulation. AMPH or vehicle was administered subcutaneously, and all $\mathrm{AMPH}$ doses refer to the free base.
In vivo microdialysis. The structure of the dialysis probe and the connector device (modified from Robinson and Whishaw, 1988) for attachment to the animal are illustrated in Figure 1. Artificial CSF (147 $\mathrm{mM} \mathrm{NaCl}, 2.3 \mathrm{mM} \mathrm{CaCl}_{2}, 0.9 \mathrm{~mm} \mathrm{MgCl}_{2}, 4.0 \mathrm{~mm} \mathrm{KCl}$; $\mathrm{pH} 6.3$ ) was delivered at the rate of $3 \mu \mathrm{l} / \mathrm{min}$ through a $50 \mathrm{~cm}$ length of Micro-line ethyl vinyl acetate tubing to a $4 \mathrm{~cm}$ length of 25 gauge stainless steel tubing. A Spectra/Por hollow fiber ( $M W$ cut-off 6000 , o.d. $250 \mu \mathrm{m}$ ), attached with epoxy to the other end of the stainless steel tubing, extended $2.25 \mathrm{~mm}$ and was sealed with a $0.25 \mathrm{~mm}$ epoxy plug to serve as the dialysis sac. A $50 \mathrm{~cm}$ length of fused silica $(150 \mu \mathrm{m}$ o.d. $\times 75$ $\mu \mathrm{m}$ i.d.) was threaded through the inflow and stainless steel tubing into the dialysis sac to within $0.25 \mathrm{~mm}$ of the epoxy plug and served as the outflow tubing. The dialysis probe was inserted into the stainless steel connector assembly, adjusted in length for the designated site of dialysis, and firmly seated with a set screw. The inflow and outflow lines proceeded via stainless steel spring stock to an Instech miniature swivel and a collection tube, containing $5 \mu \mathrm{l} 1 \mathrm{~N} \mathrm{HCl}$, located outside of the sound-proofed behavioral apparatus. The remote location of the collection tube allows for frequent repetitive sample collection without disturbing the animal's ongoing behaviors (Fig. 1). The swivel was attached to an appropriately counterweighted balance bar to allow the animal to engage fully in all behaviors typical to this environment. The $50 \mathrm{~cm}$ length of fused silica outflow tubing introduced a $45 \mathrm{sec}$ lag between the site of perfusion and the collection tube, for which all values have been corrected.

Concomitant behavioral and biochemical characterizations were performed in custom-designed activity chambers $(12 \times 12 \times 15$ inches $)$, described in detail by Segal and Kuczenski $(1987 \mathrm{a}, \mathrm{b})$ and modified to accommodate the dialysis methodology. Each chamber was located in a sound-proofed ventilated cabinet. Food and water were available ad libitum and lighting was maintained on the reverse light/dark cycle. The dialysis probe was inserted during the evening prior to the experimental manipulation. The tip of the dialysis probe, which extended approximately $4.6 \mathrm{~mm}$ beyond the end of the guide cannula, was directed into the anterior striatum at a site $1.0 \mathrm{~mm}$ anterior to bregma, 


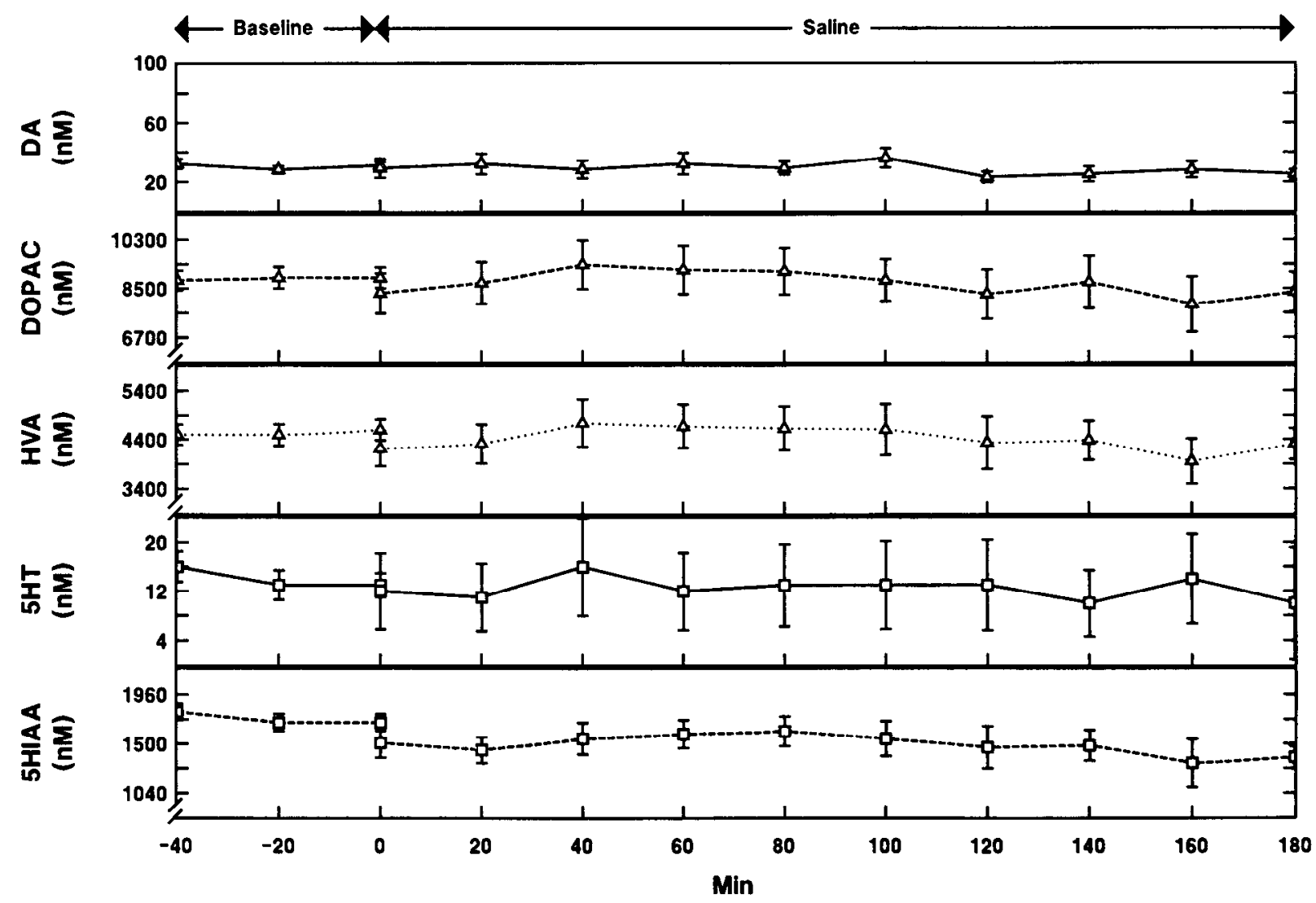

Figure 2. Basal striatal dialysate concentrations of dopamine, 5-HT, and their metabolites. Dialysate flow and sample collection were initiated $16 \mathrm{hr}$ after dialysis probe insertion $(n=56)$, and $2 \mathrm{hr}$ prior to s.c. saline administration $(n=6)$.

$\pm 2.8 \mathrm{~mm}$ from the midline, and $6.2 \mathrm{~mm}$ below the dura, according to the atlas of Paxinos and Watson (1986). The animal was allowed to acclimate to the test apparatus for about $16 \mathrm{hr}$ overnight, at which time dialysis was initiated and samples were collected at 20 min intervals for $2 \mathrm{hr}$ to establish baseline parameters. Following drug adminstration, samples were generally collected at 10 min intervals for the initial 40 $\mathrm{min}$, and then at $20 \mathrm{~min}$ intervals to the end of the drug response. At the end of the experiment, the animal was killed by decapitation, and the brain was placed in $3 \%$ formalin. Examination of $20 \mu \mathrm{m}$ cryostat sections provided histological verification of the dialysis site. Data were included only for those animals found to have accurate placements (approximately $95 \%$ of rats).

Behaviors were monitored continuously by computer. Movements of the animal between quadrants of the chamber (crossovers) were detected through contacts in the floor grid, and rearing was registered when the animal contacted the wall touchplate 5 inches above the floor. In addition, contacts with water in a sipper tube, or with a recessed metal food container, provided measures of drinking and eating, respectively. To allow a more detailed analysis of the qualitative features of the behavioral response, each animal was also videotaped throughout the drug response. Raters who were unaware of the specific experimental conditions recorded behaviors using procedures described in detail by Segal and Kuczenski (1987a).

Biochemical analyses. Levels of DA, DOPAC, HVA, 5HIAA, and 5-HT in dialysates were assessed as previously described (Kuczenski, 1986) by direct injection of 20 or $50 \mu \mathrm{l}$ aliquots into an HPLC-EC system consisting of a Waters Model 510 pump set at $1 \mathrm{ml} / \mathrm{min}$, a Waters Resolve ODS-C18 $5 \mu$ analytical column $(150 \times 4.6 \mathrm{~mm})$ maintained at $35^{\circ} \mathrm{C}$, a Waters model 460 electrochemical detector, and a glassy carbon electrode maintained at $+0.7 \mathrm{~V}$ relative to a $\mathrm{Ag} / \mathrm{AgCl}$ reference electrode. The mobile phase consisted of $0.08 \mathrm{M}$ citric acid, $7 \%$ methanol, $0.1 \mathrm{~mm} \mathrm{Na}{ }_{2}$ EDTA, and $0.8 \mathrm{~mm}$ octane sulfonate, adjusted with $\mathrm{NaOH}$ to $\mathrm{pH} 3.7-4.2$, depending on the condition of the analytical column. Quantitation limits for the amines $(3 \times$ background noise) were near $5 \mathrm{fmol} /$ injection. The recovery of the various compounds for each dialysis probe was estimated in vitro at $20^{\circ} \mathrm{C}$ on the day of each experiment. Probes were typically reused for 3-4 experiments with little change in recovery from day to day. The 2-mm-length probes yielded recoveries of $2-5 \%$. All values were corrected for individual probe recovery to allow comparisons of the extracellular concentration of each compound between animals.

\section{Results}

Basal concentrations of transmitters and their metabolites With initiation of dialysate flow $16 \mathrm{hr}$ after probe insertion, levels of transmitters and their metabolites rapidly stabilized during the first $60 \mathrm{~min}$ and then remained constant during the subsequent $60 \mathrm{~min}$ immediately prior to drug administration (Fig. 2). Consistent with previous reports (Zetterstrom et al., 1983, 1984; Imperato and Di Chiara, 1985; Westerink and Tuintc, 1986; Westcrink ct al,, 1988), concentrations of transmitter metabolites were always 100 - to 400 -fold greater than the concentration of the parent amines. Mean extracellular basal concentrations (nM), corrected for probe recovery, were as follows: DA, $28.8 \pm 2.6$; DOPAC, $8780 \pm 380$; HVA, $4520 \pm$ $210 ; 5$-HT, $14.3 \pm 2.6$; and 5HIAA, $1740 \pm 80(n=56)$. In some experiments, dialysates were analyzed during the $3 \mathrm{hr}$ immediately after insertion of the probe. Under these conditions, stable transmitter and metabolite concentrations were achieved within $90-120 \mathrm{~min}$ and were virtually identical to concentrations observed when dialysate flow was reinitiated on the subsequent morning.

Analyses of Pearson correlation coefficients indicated no significant correlations between the basal concentrations of DA 



Figure 3. Striatal dopaminergic and serotonergic response to a single injection of $0.5(l e f t ; n=11)$ or $1.0($ right; $n=5) \mathrm{mg} / \mathrm{kg}$ AMPH.

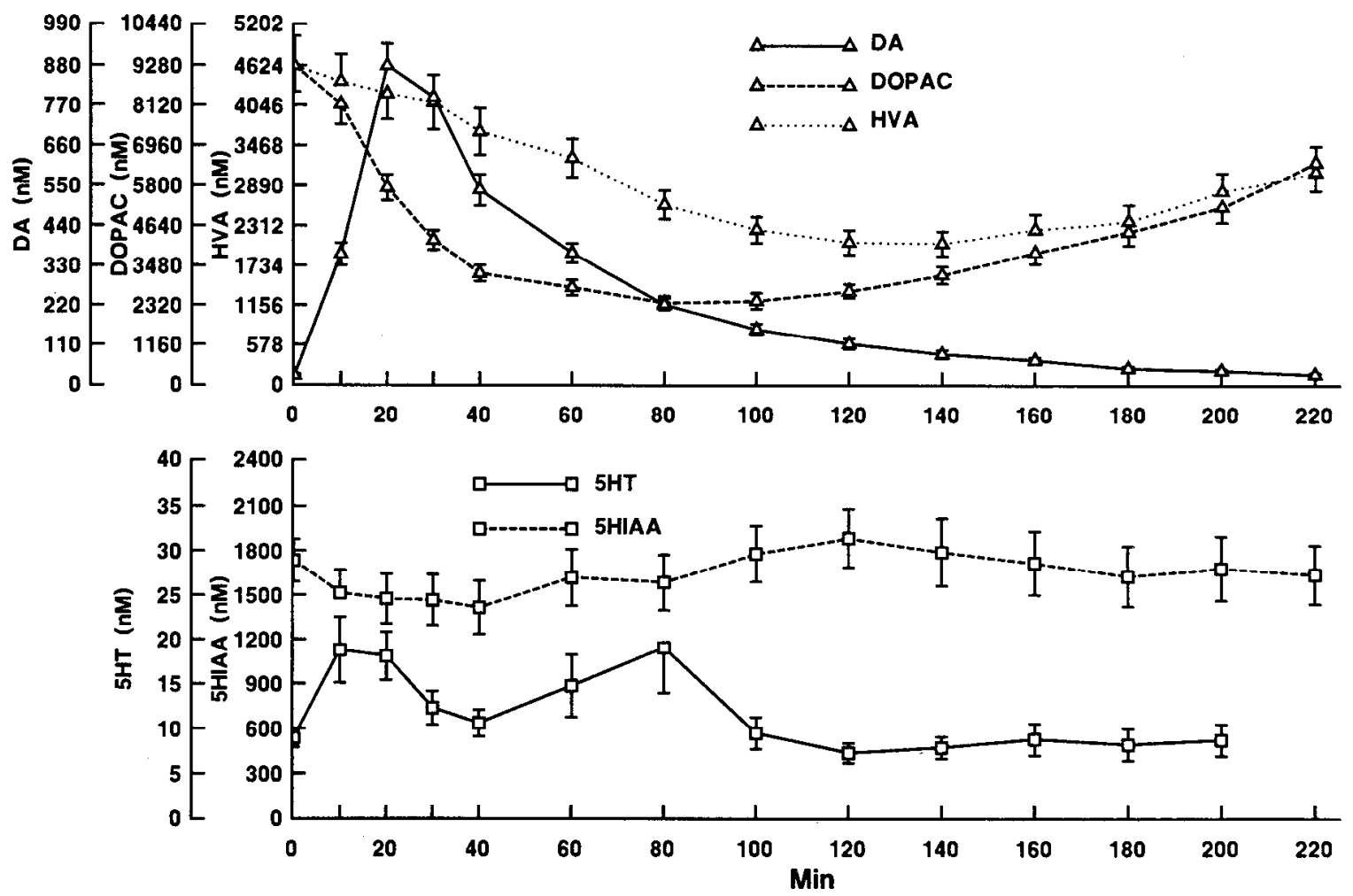

Figure 4. Striatal dopaminergic and serotonergic response to a single injection of $2.0 \mathrm{mg} / \mathrm{kg} \mathrm{AMPH}(n=19)$. 
2.5 AMPH

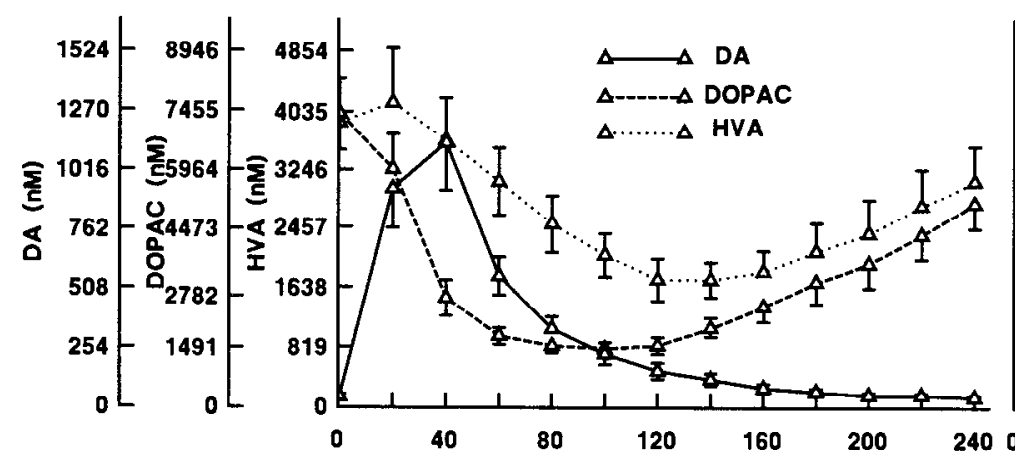

5.0 АMPH
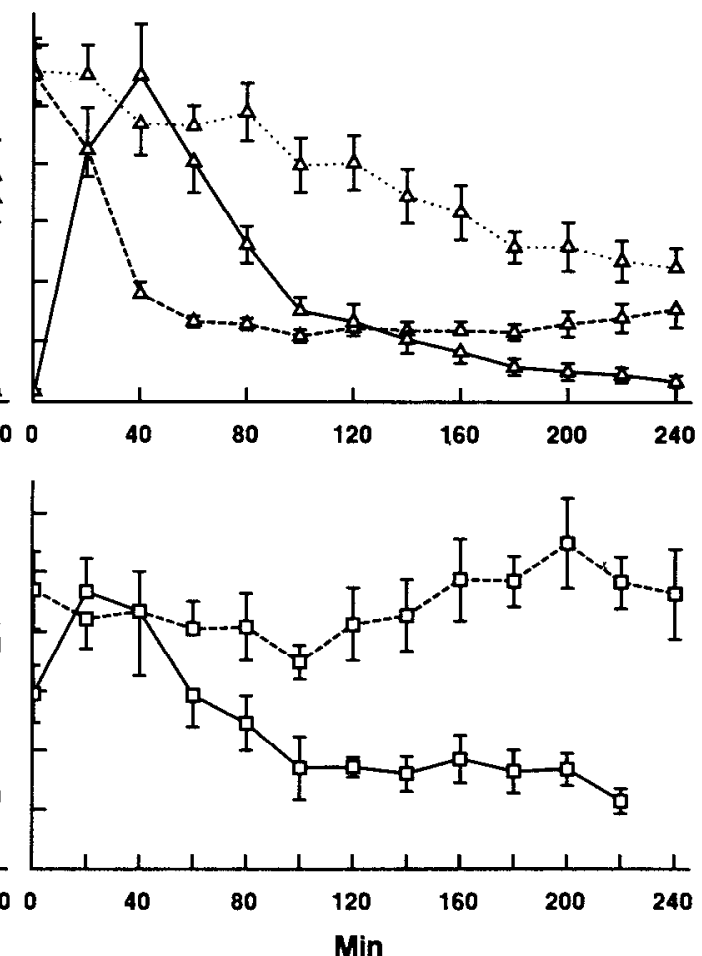

Figure 5. Striatal dopaminergic and serotonergic response to a single injection of $2.5(l e f t n=7)$ or $5.0(r i g h t ; n=7) \mathrm{mg} / \mathrm{kg} \mathrm{AMPH}$.

and either of its metabolites, DOPAC or HVA, nor between the concentrations of 5-HT and its metabolite, 5HIAA. In contrast, concentrations of DOPAC and HVA were highly correlated $(R$ $=0.87 ; p<0.001)$. In addition, significant correlations were observed between 5HIAA and both DOPAC $(R=0.59 ; p<$ $0.001)$ and HVA $(R=0.63 ; p<0.001)$. Surprisingly, a significant correlation was also obtained between DA and 5-HT $(R$ $=0.45 ; p=0.003$ ). In the absence of experimental manipulation, dialysate concentrations of DA, 5-HT, and their metabolites remained constant during the course of a 6-8 hr assessment (data not shown), and the systemic administration of saline did not significantly alter these concentrations (Fig. 2).

\section{Effects of AMPH on dialysate levels of transmitters and metabolites}

The time course of effects of AMPH over the dose range 0.5$5.0 \mathrm{mg} / \mathrm{kg}$ on DA, 5-HT, and their metabolites are presented in Figures 3-5. To facilitate comparison of dose-response relationships, average extracellular concentrations over selected time intervals are presented in Figure 6. ANOVA of baseline concentrations across AMPH dose groups reveded no significant variations. Therefore, the effects of AMPH on striatal amines were determined by comparing extracellular concentrations following AMPH to predrug baseline concentrations.

\section{Dopaminergic response}

Following the administration of AMPH, DA levels rose rapidly and were significantly elevated from baseline at all doses within the first interval tested (Figs. 3-5). Extracellular DA concentrations (see Fig. 6 for selected time intervals) exhibited a monotonic dose-dependent elevation. During the 0-40 min interval, which included the maximal DA response (concentrations peaked
20-40 min after drug administration for all AMPH doses), DA concentrations ranged from $143 \pm 17 \mathrm{~nm}$ after $0.5 \mathrm{mg} / \mathrm{kg}$ to $1260 \pm 170 \mathrm{nM}$ after $5.0 \mathrm{mg} / \mathrm{kg}$. The duration of the response was also dose related; DA concentrations were not significantly different from baseline by $80 \mathrm{~min}$ following $0.5 \mathrm{mg} / \mathrm{kg}$ (Figs. 3 , 6) but remained elevated for $220 \mathrm{~min}$ following $5.0 \mathrm{mg} / \mathrm{kg}$ (Figs. $5,6)$.

In contrast to the AMPH-induced rise in DA levels, concentrations of DOPAC declined significantly following all doses of AMPH tested (Figs. 3-6). However, the temporal features of the decline did not parallel the elevation in DA concentrations. For example, during the $0-40$ min interval (Fig. 6), the significant decreases in DOPAC concentrations were not dose dependent. Significant dose-dependent differences in DOPAC concentrations were obtained at later intervals (40-100 min: $F=$ $13.73, p<0.001$; 100-160 min: $F=22.02, p<0.001$; Fig. 6). Such differences presumably reflect the earlier recovery of DOPAC at the lower doses $(0.5$ and $1.0 \mathrm{mg} / \mathrm{kg})$. Furthermore, whereas minimal DOPAC concentrations after $1.0 \mathrm{mg} / \mathrm{kg}(2430$ $\mathrm{nM} ; 23 \%$ of baseline at $60 \mathrm{~min}$ ) were significantly lower than after $0.5 \mathrm{mg} / \mathrm{kg}$ (3130 nM; 35\% of baseline at $60 \mathrm{~min}$ ), no significant differences in the maximal effect of AMPH on DOPAC concentrations were obtained at doses of $1.0 \mathrm{mg} / \mathrm{kg}$ or higher. The absence of a dose-dependent effect of AMPH on DOPAC at doses of $1 \mathrm{mg} / \mathrm{kg}$ or greater contrasts markedly with the DA response, suggesting a dissociation between these 2 measures of DA function.

AMPH also decreased HVA concentrations at all doses tested (Figs. 3-6). The decline was time-delayed relative to both the increase in DA concentrations and the decreasc in DOPAC concentrations, i.e., in contrast to the effects of AMPH on DA and DOPAC, significant effects of AMPH on HVA concentra- 
Figure 6. Dose-response relationships of AMPH-induced changes in striatal dialysate concentrations of dopamine, 5-HT, and metabolites. Each value is the mean concentration \pm SEM for the indicated time interval. Shaded areas represent mean \pm SEM basal concentrations of metabolites for all animals. $* p<0.05 ;{ }^{* *} p<0.01 ; * * * p<$ 0.001 compared to within-group predrug baseline concentrations. $\dagger p<0.05$; t† $p<0.01 ;$ it $p<0.001$ compared to the $2.0 \mathrm{mg} / \mathrm{kg}$ AMPH response.
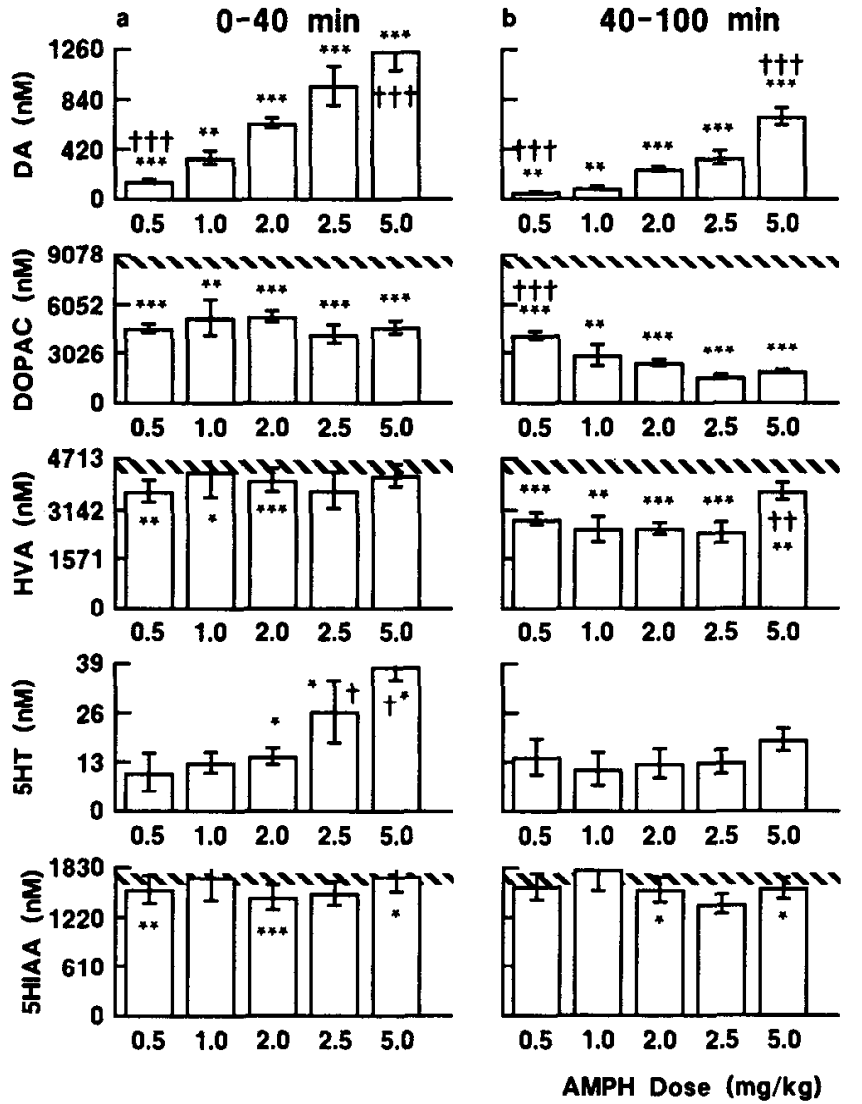

c 100-160 min

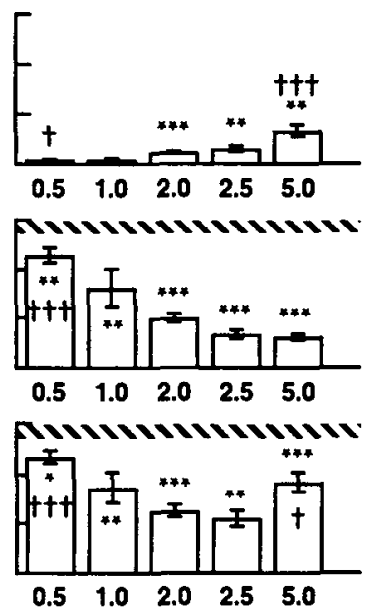

$\begin{array}{llll}1.0 & 2.0 & 2.5 & 5.0\end{array}$

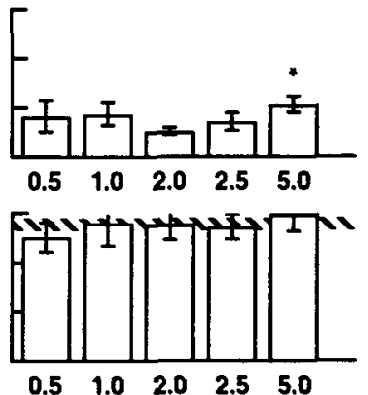

tions were not obtained during the initial 20 min after AMPH administration. Furthermore, the dose-response effects of AMPH on HVA were not monotonic. Thus, during the 40-100 min interval following AMPH administration, when HVA concentrations exhibited a significant decrease in response to all doses of AMPH (Fig. 6), HVA concentrations after $2.0 \mathrm{mg} / \mathrm{kg} \mathrm{AMPH,}$ for example, were significantly lower than after $5.0 \mathrm{mg} / \mathrm{kg}(t=$ $3.24, p<0.05$; ANOVA followed by $t$ tests with Bonferroni correction). By the 100-160 min interval, HVA concentrations for the $2.0 \mathrm{mg} / \mathrm{kg}$ group were also significantly lower $(t=5.38$, $p<0.001)$ than the $0.5 \mathrm{mg} / \mathrm{kg}$ group, reflecting the more rapid return of the metabolite levels toward baseline after the lower dose.

The apparent dissociation of the temporal patterns of extracellular DA, DOPAC, and HVA concentrations induced by AMPH is also evident when individual animal responses are examined. The data in Figure 7 represent the dopaminergic response of 4 representative animals to $2.0 \mathrm{mg} / \mathrm{kg} \mathrm{AMPH}$. Whereas these 4 animals exhibited a 2 -fold range in peak DA levels following this dose of AMPH, neither the magnitude nor temporal features of the DOPAC or HVA responses reflected this degree of variation. Furthermore, correlational analyses failed to reveal a relationship between the AMPH-induced increase in DA concentrations and the decreases in either DOPAC or HVA within doses. In contrast, the high correlation observed between basal DOPAC and HVA concentrations also appeared throughout the duration of the response for all doses of AMPH. In addition, comparisons of the absolute magnitude of AMPHinduccd change in DOPAC and HVA from baseline levels were also significant, both across and within doses, for $0.5,1.0$, and $2.0 \mathrm{mg} / \mathrm{kg}$. For example, during the $40-100 \mathrm{~min}$ interval, when both DOPAC and HVA achieved their maximal declines, correlation coefficients for the magnitude of change in DOPAC and HVA from baseline values were as follows: $0.5 \mathrm{mg} / \mathrm{kg}, R=0.86$, $p<0.001 ; 1.0 \mathrm{mg} / \mathrm{kg}, R=0.75, p<0.001 ; 2.0 \mathrm{mg} / \mathrm{kg}, R=$ $0.88, p<0.001$.

\section{Serotonergic response}

The administration of AMPH resulted in a significant, dosedependent increase in striatal extracellular levels of 5-HT (Figs. 3-6). The significant increases in 5-HT concentrations were confined to the initial 40 min interval following the higher doses of AMPH (2.0-5.0 mg/kg; Fig. 3-6). Concomitantly, 5HIAA concentrations declined by 10-20\%; however, ANOVA failed to reveal a significant effect as a function of AMPH dose. Although, as noted earlier, basal levels of 5-HT and 5HIAA were not significantly correlated, 5-HT concentrations across all doses during the 0-40 min interval after AMPH administration exhibited a significant correlation both with 5HIAA concentrations during this interval $(R=0.58, p<0.001)$, as well as with basal 5HIAA levels $(R=0.51, p<0.002)$.

\section{Relationship between $A M P H$-induced changes in $D A$ and 5-HT}

Concomitant assessment of DA and 5-HT parameters provided for evaluation of potential relationships between AMPH-induced changes in the 2 neurotransmitter systems. The significant correlations observed between basal concentrations of both $D O$ PAC and HVA with 5HIAA were also apparent during the 0 $40 \mathrm{~min}$ interval after drug injection $(R=0.48, p<0.001$, and $R=0.62, p<0.001$, respectively). Similarly, a significant correlation between DA and 5-HT was also obtained during the 
Dopamine

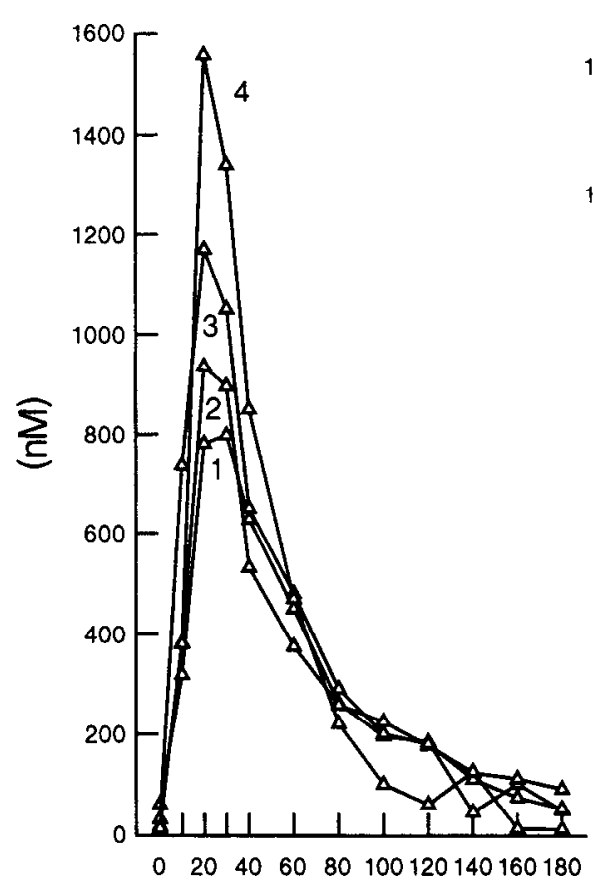

DOPAC

HVA
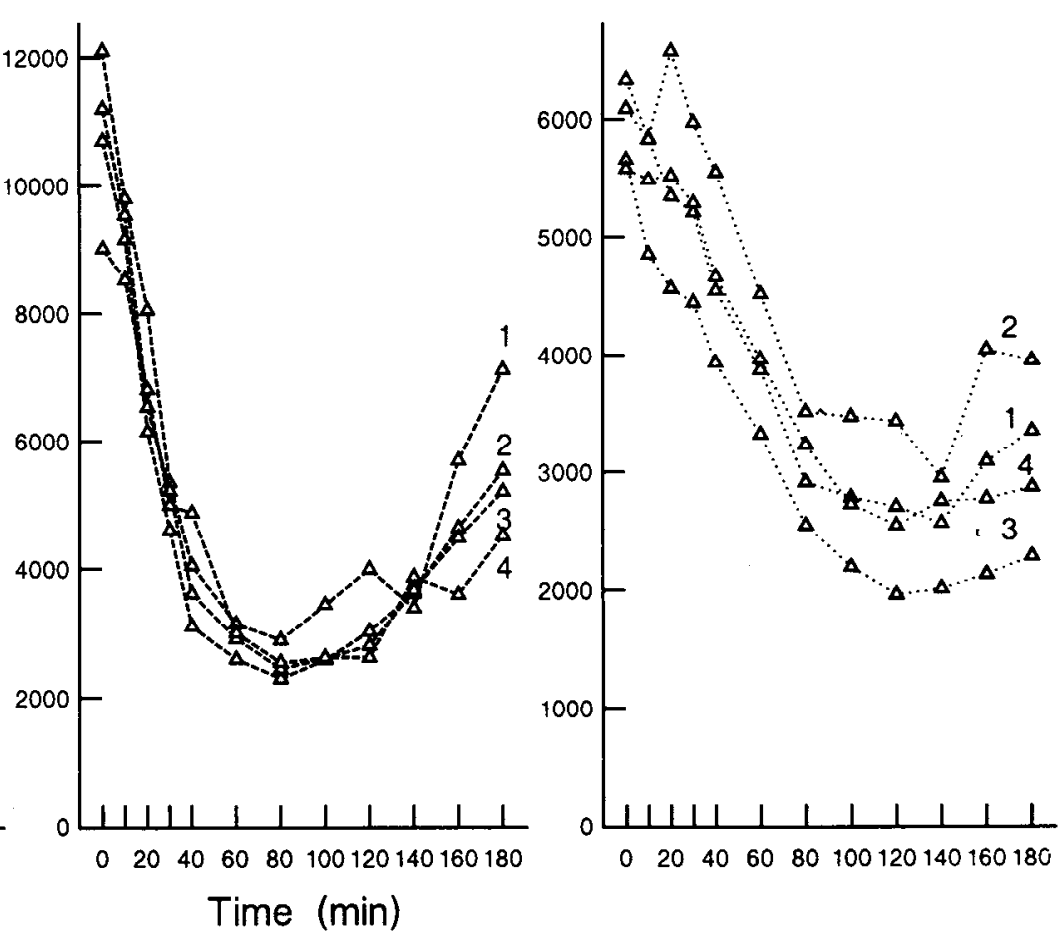

Figure 7. Temporal pattern of dopaminergic response for 4 representative animals to $2.0 \mathrm{mg} / \mathrm{kg} \mathrm{AMPH}$.

$0-40$ min interval after AMPH administration $(R=0.71, p<$ $0.001)$.

\section{Behavioral response to $\mathrm{AMPH}$}

The administration of AMPH resulted in distinct dose-dependent behavioral profiles, and the temporal pattern of the responses for selected doses of the drug are presented in Figure 8 , with dose-response relationships summarized in Figure 9. DA and 5-HT concentrations, assessed during the behavioral response, are included for comparison. The lowest doses of AMPH tested, $0.5 \mathrm{mg} / \mathrm{kg}$ (Fig. 8) and $1.0 \mathrm{mg} / \mathrm{kg}$ (data not shown), produced a behavioral response profile consisting predominantly of enhanced locomotion (reflected in an increase in crossovers). The response included brief episodes of continuous sniffing in the absence of the more intense forms of stereotypy, i.e., repetitive movements or oral behaviors. After $0.5 \mathrm{mg} / \mathrm{kg} \mathrm{AMPH}$, the duration of increased crossovers paralleled approximately the temporal pattern of the elevated DA concentrations. However, the DA and locomotor response pattern were markedly dissociated at $1.0 \mathrm{mg} / \mathrm{kg}$ AMPH. That is, DA concentrations peaked at $430 \pm 90 \mathrm{nM} 20$ min following drug administration (Fig. 3), whereas the elevated locomotor response remained relativcly stable for $60 \mathrm{~min}$, during which time DA levels declined more than 3 -fold to $130 \pm 17 \mathrm{~nm}$.

The locomotor response to $2.0 \mathrm{mg} / \mathrm{kg}$ AMPH (Fig. 8) shows a prolonged period of enhanced locomotion that includes a brief dip in crossovers (40-70 $\mathrm{min}$ ) corresponding to the appearance of a focused stereotypy phase in a subgroup of the animals. These results are consistent with our earlier finding that following administration of an intermediate dose of AMPH (1.5-2.0 $\mathrm{mg} / \mathrm{kg}$ ), some animals exhibit only enhanced locomotion, whereas other animals display focused stereotypies (Segal and
Kuczenski, 1987a). A dissociation between AMPH-induced behaviors and DA concentrations was apparent especially during the later phases of the response. For example, in those animals that exhibited focused stereotypy, repetitive head movements remained prominent when $\mathrm{DA}$ release declined to levels below those associated with the initial period of locomotion. This dose of AMPH also significantly increascd 5-HT levels but only during the initial $20 \mathrm{~min}$ following drug administration (paired $t$ test, $p<0.01$ ).

At a dose of $5 \mathrm{mg} / \mathrm{kg}$ (Fig. 8), a multiphasic response pattern emerged in all animals. The rapid decline in crossovers, which occurred within the first $30 \mathrm{~min}$ after drug administration, paralleled the emergence of oral stereotypies persisting for as long as 210 min after drug injection. After the oral stereotypy phase, individual animals exhibited varied response profiles, including enhanced locomotion, episodes of focused sniffing, and repetitive movements.

The temporal pattern of these behavioral changes contrasted markedly with the DA and 5-HT response profiles. DA concentrations peaked at 20-40 min after AMPH administration, corresponding to the onset of oral stereotypies, but then declined 5 -fold while the behavioral response remained relatively constant. In addition, 5-HT concentrations were significantly elevated only during the initial $40 \mathrm{~min}$ of the drug response.

In addition to the temporal dissociation of the biochemical and behavioral response patterns at each AMPH dose, comparison of the dose-response patterns for DA and 5-HT with the various behavioral components (summarized for selected intervals in Fig. 9) revealed no simple relationships. Whereas DA and 5-HT concentrations exhibited progressive increases as a function of AMPH dose, an inverted $U$-shaped response was obtained for locomotor activity and repetitive movements, while 
0.5 AMPH

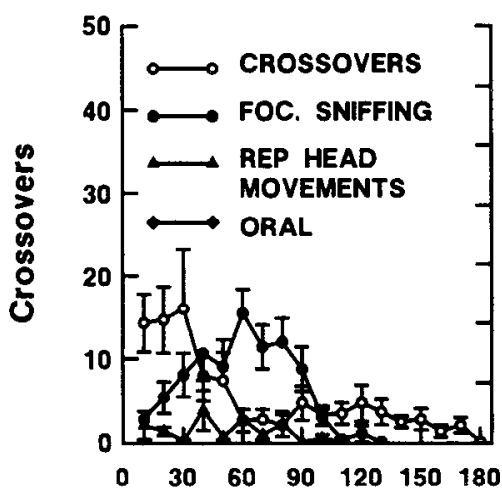

$2.0 \mathrm{AMPH}$

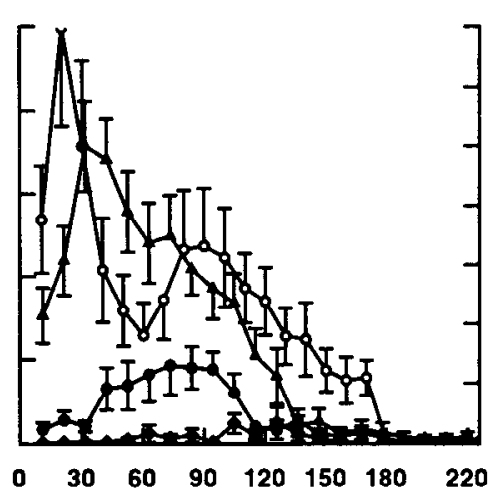

5.0 AMPH

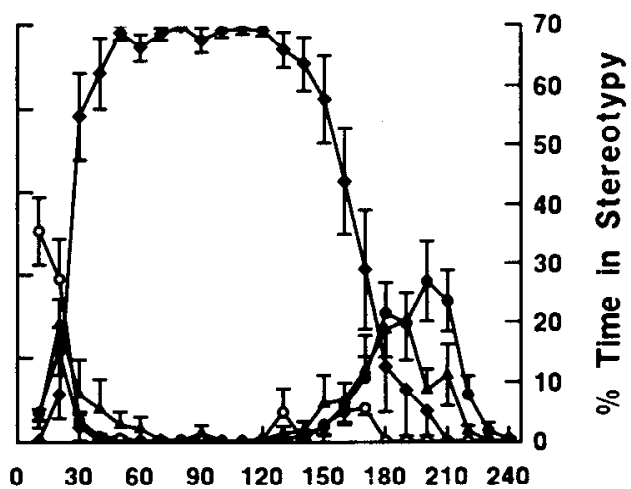

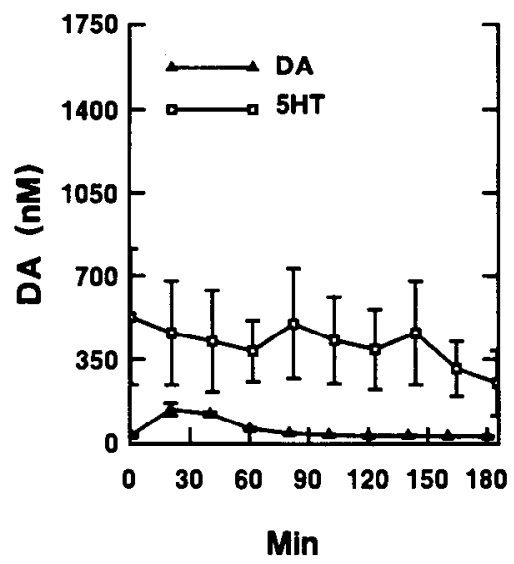
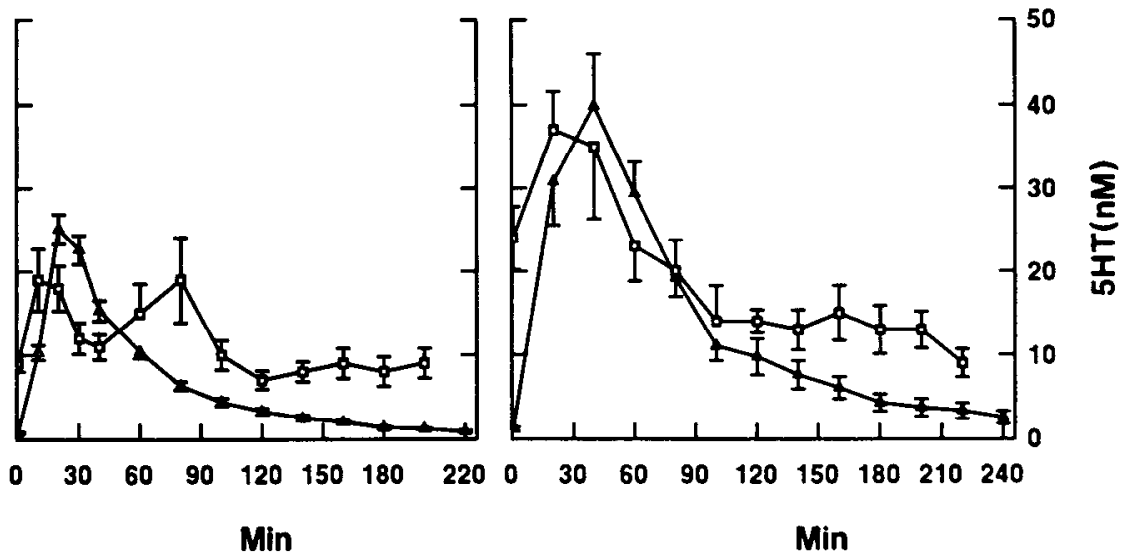

Figure 8. Temporal pattern of behavioral and concomitant neurotransmitter response to a single injection of the indicated dose of AMPH. Each value represents the mean \pm SEM.

oral stereotypies were evident only at the highest dose tested. Consistent with these observations, analyses of Pearson correlation coefficients revealed significant relationships across all doses only between the total stereotypy response and both DA $(R=0.82, p<0.001)$ and 5 -HT $(R=0.49, p<0.05)$. A significant correlation was also obtained between baseline levels of 5-HT and the total stereotypy response $(R=0.43, p<0.05)$.

Individual variations in biochemical and behavioral responsivity to AMPH were compared through correlational analyses at selected time intervals of the AMPH response profile. Following the administration of 0.5 or $1.0 \mathrm{mg} / \mathrm{kg} \mathrm{AMPH}$, doses promoting predominantly locomotor activation, no significant correlation between the magnitude of individual animal locomotor response and the increase in dialysate DA concentrations was obtained.

Similarly, in response to $2.0 \mathrm{mg} / \mathrm{kg}$ AMPH, individual animals exhibited a broad range of behavioral response patterns and dialysate DA and 5-HT concentrations. Correlational analyses revealed no significant relationships between levels of DA and the expression of individual components of the behavioral response. For example, animals representing the low and high ends of the DA response range showed similar behavioral patterns (Fig. 10). However, significant correlations were obtained for the relationship between 5-HT concentrations and both repetitive head movements and the total stereotypy score during the 0-60 min (repetitive movements, $R=-0.61, p<0.05$; total stereotypy, $R=-0.79, p<0.01$ ) and $60-120 \mathrm{~min}$ (repetitive movements, $R=-0.90, p<0.01$; total stereotypy, $R$ $=-0.86, p<0.05$ ) intervals.
Individual biochemical and behavioral response profiles to $5.0 \mathrm{mg} / \mathrm{kg}$ AMPH were also compared. As illustrated for 4 representative animals in Figure 11 , in contrast to the relatively uniform behavioral response, there was a wide range of transmitter concentrations. That is, whereas these animals exhibited a 3-fold range of peak DA concentrations, the relative occurrences of stereotyped behaviors were not distinguishable. No significant correlations between either DA or 5-HT concentrations and oral behaviors were obtained during the 0-140 min interval. However, during the 160-200 min interval, when oral behaviors in all animals began to decline, significant correlations were obtained between concentrations of DA and the occurrence of oral behaviors $(R=0.98, p<0.001)$, and between concentrations of 5-HT and repetitive head movements $(R=-0.90$, $p=0.035$ ).

The absence of a significant correlation between peak DA concentrations and the corresponding behavior is further illustrated by a comparison of the response patterns of selected animals treated with 2.0 or $5.0 \mathrm{mg} / \mathrm{kg} \mathrm{AMPH}$ (Fig. 12). These data clearly demonstrate that similar changes in DA produced by the 2 doses can be associated with qualitatively different behaviors.

\section{Discussion}

In vivo sampling techniques such as intracerebral microdialysis allow for continuous access to extracellular neurotransmitter concentrations in awake, freely moving animals. These procedures provide a more direct approach to the examination of brain/behavior relationships than has been possible with tra- 

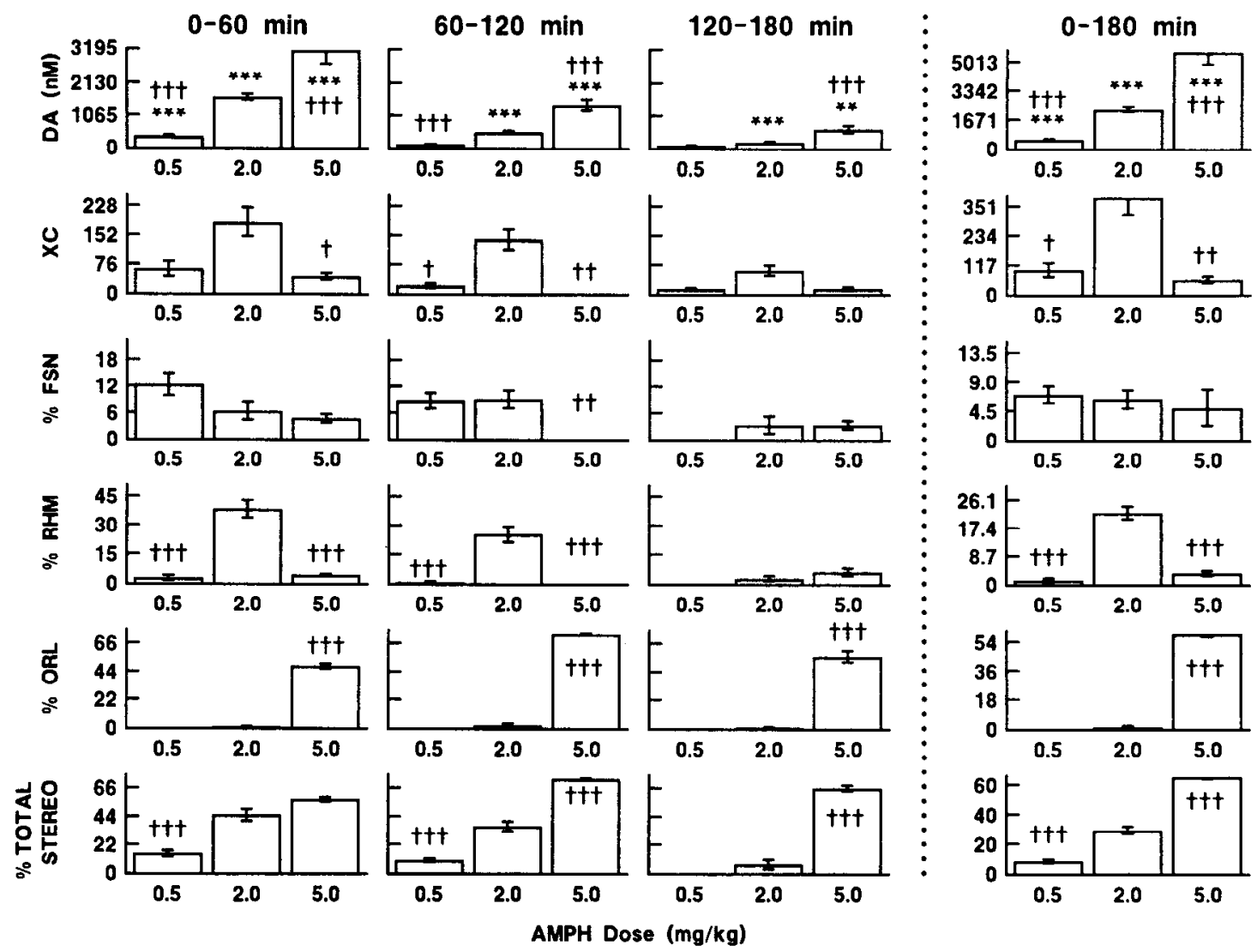

Figure 9. Dose-response relationships of AMPH-induced change in striatal dopamine compared with the presence of specific drug-induced behaviors over the specified time interval. ${ }^{*} p<0.05 ; * *<<0.01 ; * * *<0.001$ compared to within-group predrug baseline concentrations. $\dagger p$ $<0.05 ; \dagger p<0.01 ;+\dagger+p<0.001$ compared to the $2.0 \mathrm{mg} / \mathrm{kg}$ AMPH response.

ditional post-mortem techniques. Our results represent a syslematic characterization of AMPH-induced changes in neostriatal DA, 5-HT, and their metabolites along with the corresponding behavioral response profile. The data reveal a variety of relationships both within and between these neurotransmitter systems and suggest a behavioral role that is not entirely consistent with previous speculations based on more indirect approaches.

\section{Biochemical response characteristics}

Following dialysis probe inscrtion, basal concentrations of the neurotransmitters and their metabolites stabilized within 90$120 \mathrm{~min}$ at levels comparable to values previously reported using microdialysis (Zetterstrom et al., 1983, 1984; Imperato and Di Chiara, 1985; Westerink and Tuinte, 1986; Westerink et al., 1988). Levels remained relatively constant through $24 \mathrm{hr}$ after placement, suggesting no progressive change in the tissue or in the dialysis membrane. During the three 20 min sampling intervals $16 \mathrm{hr}$ after probe insertion and immediately prior to drug administration, concentrations exhibited little fluctuation, and levels of the transmitter metabolites remained several hundred-fold greater than the parent amines.

Analyses of Pearson correlation coefficients revealed no significant correlations between DA and either of its metabolites, DOPAC and HVA, consistent with the recent results of Robinson and Whishaw (1988), whereas concentrations of the 2 metabolites were highly correlated. DOP $\Lambda \mathrm{C}$ presumably arises from intraneuronal DA metabolism, and the high correlation between DOPAC and HVA levels is consistent with the sug- gestion (Westerink, 1985) that HVA originates almost exclusively from DOPAC as a second metabolite of DA. To the extent that dialysate levels of DA parallel synaptic concentrations, the absence of a relationship between extracellular D $\Lambda$ and its metabolites would therefore suggest a dissociation between DA release and its uptake, on the one hand, and DA metabolism through MAO, on the other. This suggestion is consistent with previous post-mortem data (Braestrup, 1977; Di Giulio et al., 1978; Westerink and Spaan, 1982) that the administration of drugs which block the uptake of DA do not alter levels of DOPAC or IIVA. Thus, at least under baseline conditions, most of the metabolites in dialysates appear to originate from intraneuronal metabolism of excess transmitter and do not reflect transmitter release.

Likewise, no significant correlations were obtained between concentrations of 5-HT and 5HIAA, also consistent with the suggestion that 5HIAA reflects intraneuronal metabolism of excess 5-HT and not 5-HT release (Grahame-Smith, 1971; Hammond et al., 1983; Kuhn et al., 1985). Thus, in the presence of steady-state intracellular transmitter levels, the synthesis of both DA and 5-HT contributes substantially to metabolism that is dissociated from the utilization processes. These observations suggest that neither metabolite concentrations nor transmitter synthesis can provide an accurate index of functional neurotransmission in striatal dopaminergic or serotonergic systems.

Interestingly, concentrations of both DOPAC and HVA were highly corrclated with concentrations of 5HIAA. A high correlation between HVA and 5HIAA in CSF has recently been described by Becker et al. (1988) in rat CSF. Since DOPAC and 



Figure 10. Comparison of striatal dopamine with the presence of repetitive head movements for representative animals in response to $2.0 \mathrm{mg} /$ $\mathrm{kg}$ AMPH. Left, Values represent the change in DA concentration and the percentage of time spent engaged in repetitive movements cumulated over $2 \mathrm{hr}$ after drug administration. Right, Mean \pm SEM for the 2 subgroups of animals. $* * * p<0.001$.

5HIAA each appear to originate primarily from intraneuronal metabolism of their respective excess neurotransmitters, the significant correlation between these metabolites would imply a close relationship between the rates of synthesis of DA and 5-HT. In addition, the observation that extracellular concentrations of DA and 5-HT are also highly correlated indicates a linkage between neuronal release of these transmitters. These data therefore suggest the intriguing possibility that striatal dopaminergic and serotonergic systems may be functionally interdependent, a possibility we are currently investigating.

Concentrations of the neurotransmitters and their metabolites remained constant at baseline levels for at least $4 \mathrm{hr}$ following saline administration, suggesting that changes in these parameters following AMPH administration provide an accurate representation of specific pharmacological effects of the drug. Therefore, predrug baseline values for each animal could be utilized as reference points to quantitate the AMPH-induced biochemical profile. In this regard, it is important to note that no relationship was apparent in individual animals between the absolute magnitude of the DA response to AMPH and the basal concentration of the transmitter at any dose tested, i.e., low or high basal DA did not determine the degree of response to AMPH.

The acute administration of increasing doses of AMPH over the range $0.5-5.0 \mathrm{mg} / \mathrm{kg}$ resulted in progressively enhanced extracellular concentrations of DA, proportional both in magnitude and duration to the dose of the drug. DA concentrations rose rapidly and peaked within $40 \mathrm{~min}$ of AMPH administration, consistent with previous reports using the microdialysis technique (Zetterstrom et al., 1983; Sharp et al., 1987), and parallelling our earlier data from push-pull perfusates in anes- thetized animals (Kuczenski, 1986; Segal and Kuczenski, 1987b; Kuczenski and Segal, 1988). A more detailed resolution of the time course of the increase, achieved through biochemical sampling at 10 min intcrvals, revealcd that at all doses at AMPH maximum DA concentrations were achieved during the 10-20 min interval following drug administration (Fig. 4). The subsequent decline of DA was also rapid, falling to $50 \%$ of maximum concentrations between 60 and 80 min after drug administration.

Concomitant with the AMPH-induced elevation of extracellular DA, concentrations of the DA metabolites, DOPAC and HVA, declined, as has been observed both in post-mortem studies (Kuczenski, 1983; Westerink, 1985) and in previous studies using either microdialysis (Zetterstrom et al., 1983, 1986; Imperato and Di Chiara, 1984) or push-pull perfusion (Kuczenski, 1986). However, no simple temporal relationship between the increase in DA and the decline in metabolites was evident at any dose of AMPH. For example, whereas DA concentrations peaked near 20 min after AMPH administration at all doses, $D O P \Lambda C$ concentrations were lowest at times ranging from 60 min after $0.5 \mathrm{mg} / \mathrm{kg}$ to $100 \mathrm{~min}$ after $5.0 \mathrm{mg} / \mathrm{kg}$. The time to minimum HVA values was even further delayed relative to maximum DA concentrations. Furthermore, whereas maximum dialysate concentrations of DA increased as a function of AMPH dose, no further decline in DOPAC was observed at AMPH doses greater than $1.0 \mathrm{mg} / \mathrm{kg}$ (Figs. 3-6; see also Zetterstrom et al., 1986), and the lowest HVA concentrations were observed at intermediate doses of AMPH rather than at the highest doses tested. Correlational analyses at various intervals throughout the response revealed no significant relationships when concentrations of DA or AMPH-induced changes in DA 


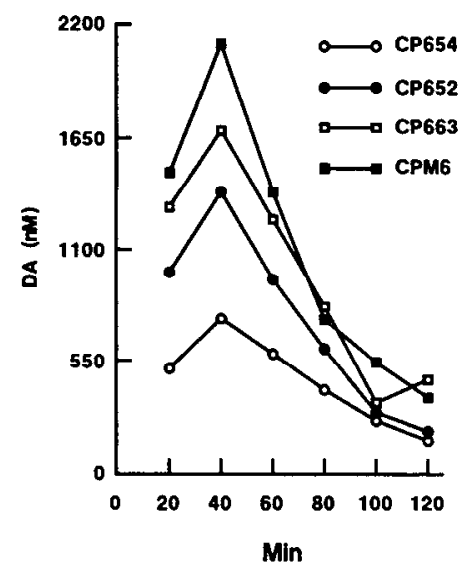

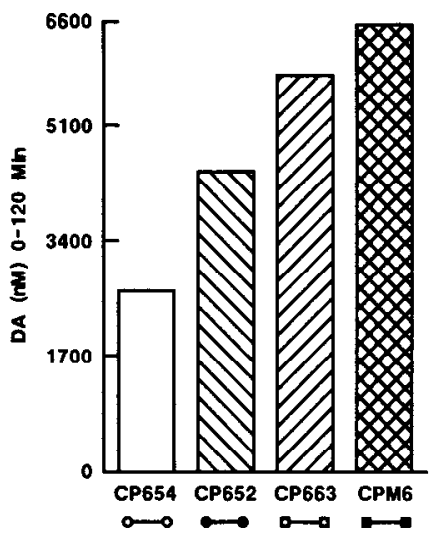

Rat No.

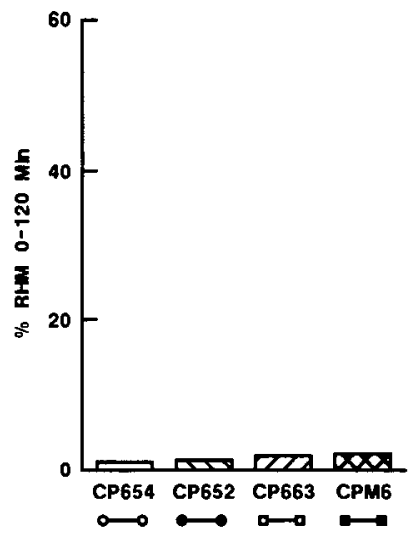

Rat No.

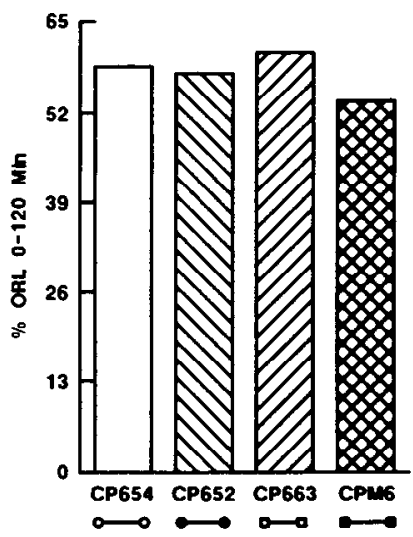

Rat No.

Figure 11. Individual animal response to $5.0 \mathrm{mg} / \mathrm{kg}$ AMPH. The temporal pattern of AMPH-induced changes in striatal D $\Lambda$ concentration is presented at the extreme left. Histograms represent cumulative changes in dialysate DA and the presence of repetitive head movements and oral stereotypies during the initial $2 \mathrm{hr}$ after drug administration.

were compared with its metabolites, either across doses or within any dose. These contrasting temporal and dose-related patterns strongly suggest that the AMPH-induced declines in DA metabolites are dissociated from the AMPH-enhanced DA release process. From these results it is clear that interpretations concerning AMPH-induced DA release cannot rely strictly on changes in DA metabolite levels.

In contrast to the absence of significant pre- or postdrug correlations between DA and its metabolites, significant positive correlations were obtained between the AMPH-induced decreases in DOPAC and HVA following the administration of doses of AMPH up to $2 \mathrm{mg} / \mathrm{kg}$. These parallel decreases suggest that the decline in HVA is a direct consequence of AMPH inhibition of DOPAC formation and that following low-dose AMPH administration released DA does not contribute significantly to HVA formation through alternative metabolic pathways. In contrast, parallel decreases in DOPAC and HVA were not observed following 2.5 and $5.0 \mathrm{mg} / \mathrm{kg}$ AMPH. We have previously argued (Kuczenski, 1983) that changes in HVA levels at high AMPH doses may arise from a shift in DA metabolism to an extraneuronal pathway via 3-methoxytyramine (3MT) as a consequence of complete DA uptake blockade. In- deed, our preliminary results confirm the recent report (Shannon et al., 1986) that only higher doses of AMPH increase dialysate levels of 3MT. Thus, at doses of AMPH promoting sufficiently high extracellular DA concentrations, perhaps due to enhanced release along with complete inhibition of DA uptake, the $3 \mathrm{MT}$ contribution to HVA formation may be sufficient to dissociate the quantitative relationship between AMPH-induced changes in HVA and DOPAC.

The AMPH-induced decrease in DA metabolites has been attributed to a variety of mechanisms, including AMPH-mediated inhibition of monoamine oxidase (MAO) or blockade of DA uptake. However, an explanation involving MAO inhibition is not consistent with the relative increase in $H V A$ concentrations at higher doses of AMPH (Figs. 5, 6), an observation that is paralleled in post-mortem measures of striatal HVA in response to AMPH (Kuczenski, 1980). Similarly, potent DA uptake blockers fail to decrease striatal DOPAC and HVA levels (Braestrup, 1977; Westerink and Spaan, 1982). In fact, blockade of DA uptake by uptake inhibitors, including $\mathrm{AMPH}$, would not be expected to significantly decrease DOPAC concentrations if, as we have argued above, metabolism of released DA contributes only a minor fraction of DOPAC formation.
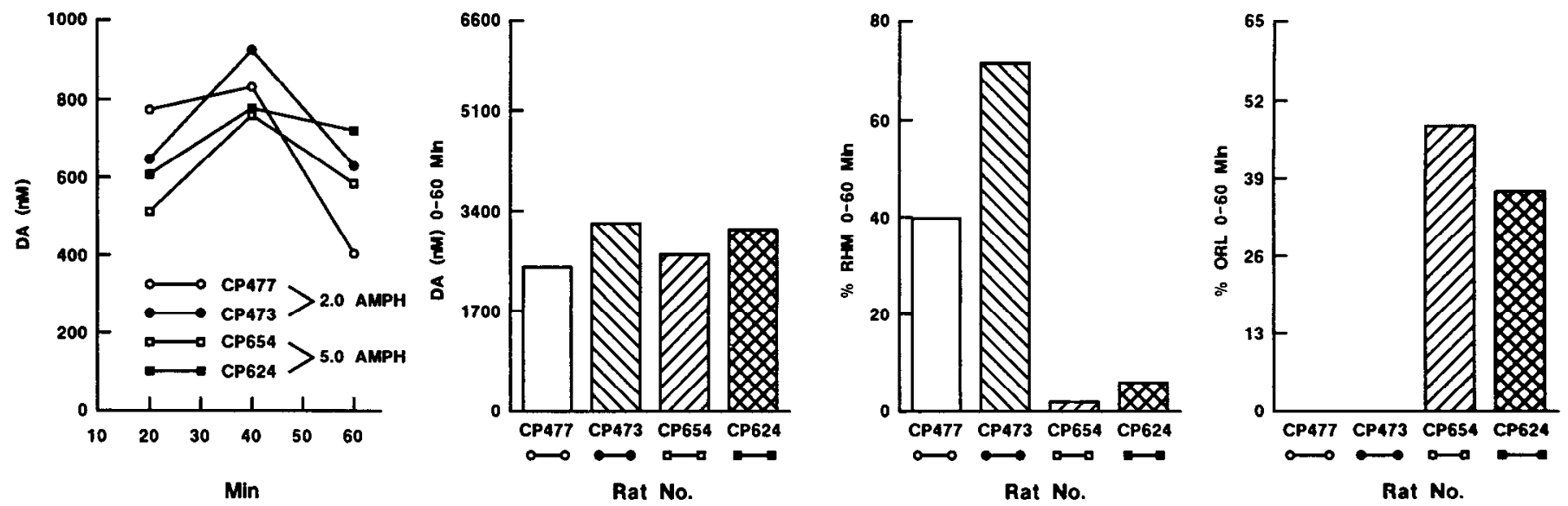

Figure 12. Response of individual representative animals to a single injection of 2.0 or $5.0 \mathrm{mg} / \mathrm{kg}$ AMPH. The temporal pattern of AMPHinduced change in striatal dialysate DA concentration is presented at the extreme left. Histograms represent cumulative changes in dialysate DA and the appearance of repetitive head movements and oral stereotypies during the initial 60 min after drug administration. 
Consistent with the dynamics of DA metabolism we have proposed above, Zetterstrom et al. (1986) recently suggested that AMPH-induced DA release depletes a cytoplasmic pool of DA that serves as the intraneuronal substrate for MAO, thereby reducing concentrations of the DA metabolites. Howcver, this suggestion was based, in part, on a significant inverse correlation between dialysate concentrations of DA and DOPAC at lower doses of AMPH, a relationship that is not supported by our data. Furthermore, a high correlation between released DA and reduced DOPAC is not entirely consistent with the variety of dynamic mechanisms, in addition to release and including ongoing DA synthesis, MAO activity, and reequilibration of vesicular with cytoplasmic DA, which all contribute to the size of the AMPH-releasable, cytoplasmic DA pool. The observation (Figs. 3-7) that extracellular DA concentrations peak and then begin to decline while DOPAC and HVA concentrations have yet to achieve their maximal declines, even at low AMPH doses, may reflect these additional factors. Thus, whereas the cytoplasmic pool provides the substrate for both AMPH-induced release and $\mathrm{MAO}$, additional mechanisms appear to obscure a simple relationship between released DA and the conversion of cytoplasmic DA to DOPAC.

In addition to the drug-induced changes in DA function described above, our analyses also provided direct evidence for AMPH-induced alterations in striatal 5-HT function and, further, revealed several DA-5-HT relationships of potential significance to striatal neuronal interactions. As with the DA response to AMPH, extracellular 5-HT increased and its metabolite, 5HIAA, decreased. However, the dose-response and temporal characteristics of the dopaminergic and serotonergic changes were different in several respects. Significant increases in dialysate 5-HT concentrations were obtained only after AMPH doses of $2 \mathrm{mg} / \mathrm{kg}$ and greater and were relatively short-lived, persisting for only $20-40 \mathrm{~min}$ after drug administration. In addition, AMPH administration decreased dialysate 5HIAA concentrations by $10-20 \%$ over the $80 \mathrm{~min}$ interval after drug administration, but these changes in 5HIAA did not significantly differ as a function of AMPH dose.

The concurrent assessment of both dopaminergic and serotonergic parameters during the response to AMPH revealed that the relationships between DA, 5-HT, and their respective metabolites were present during baseline and the drug response. Thus, over the initial 40 min time interval after AMPH injection, DA and 5-HT concentrations were significantly correlated $(R$ $=0.74, p<0.001$ ). Likewise, significant correlations were obtained between 5HIAA and both DOPAC and HVA during most of the response.

The apparent relationships between AMPH-induced changes in DA and 5-HT may simply reflect independent but parallel dose-dependent pharmacological changes. Both neurotransmitter systems exhibit many analogous metabolic and mechanistic features, and thus might be expected to respond in a parallel fashion to AMPH. However, the presence of these relationships prior to drug administration suggests a more fundamental genesis. In fact, a DA-5-HT interdependence in striatum is consistent with a catecholamine-indoleamine balance which has been hypothesized (Brodie and Shore, 1957).

\section{Behavioral/biochemical relationships}

We have previously described (Segal and Schuckit, 1983; Segal and Kuczenski, 1987b) the qualitative and quantitative characteristics of the AMPH dose-response profile, and a similar pattern of behavioral effects is obtained with concurrent dialysis, indicating that these procedures do not significantly alter the primary features of the response to AMPH. Lower doses of AMPH $(0.5$ and $1.0 \mathrm{mg} / \mathrm{kg})$ promote a prolonged period of cnhanced locomotion and intense sniffing behavior, in the absence of continuous focused stereotypy. Intermediate doses of AMPH (e.g., $2.0 \mathrm{mg} / \mathrm{kg}$ ) are transitional in the production of focused stereotypies such that some animals exhibit only enhanced locomotion in the absence of stereotypy, whereas others exhibit a prolonged period of focused stereotyped behavior consisting predominantly of continuous focused sniffing and repetitive head and limb movements (Segal and Kuczenski, 1987a). When crossover activity (Fig. 8) is averaged for all animals receiving such a transitional dose, this difference in response profiles is obscured and appears rather as a slight early depression in the prolonged behavioral activity profile. Higher doses of AMPH promote a clearly defined multiphasic response profile, including an intermediate phase during which all animals engage in focused stereotypies involving, at the highest dose tested $(5.0 \mathrm{mg} / \mathrm{kg}$, Fig. 8), prolonged and continuous oral behaviors. Considerable converging evidence suggests that quantiative changes in nigrostriatal DA function mediate many of the qualitative and quantitative changes in at least some forms of stereotypy (Creese and Iversen, 1974; Kelly et al., 1975; Kelly, 1977).

Before assessing possible behavioral/neurochemical relationships, several issues should be considered in the selection of appropriate behavioral data for comparison with neurotransmitter dynamics. For one, because of the qualitative changes that occur as a function of AMPH dose and the apparent competitive interactions between the various behavioral effects, alterations in specific response components may be difficult to interpret. Thus, whereas DA release increases in a monotonic fashion, most of the behavioral changes exhibit an inverted U-shaped relationship with increasing dose. Different optimal doses are associated with maximal levels of locomotion, focused sniffing, and repetitive head and limb movements, respectively, and oral stereotypies are observed only at the highest dose tested. It is apparent, therefore, that increasing release of striatal DA is not closely related to the expression of any of the behavioral components in the AMPH dose-response profile. However, as we have previously suggested (Segal and Geyer, 1985), one feature of the AMPH response, i.e., response perseveration, does become progressively more pronounced with increasing dose, and our data show that there is a high correlation $(R=0.82, p$ $<0.001)$ between the dose-related increase in DA and the total time spent engaged in some form of focused stereotypy. Therefore, activation of DA systems in the neostriatum may be directly related to the degree of response perseveration.

However, a simple quantitative relationship is not evident within each dose since the temporal features of the DA and predominant behavioral responses are not parallel. Thus, for example, after $1.0 \mathrm{mg} / \mathrm{kg}$, whereas DA levels peaked at $20 \mathrm{~min}$ following drug administration and then rapidly declined (Fig. 3 ), locomotion was maintained near maximal levels from 20 to 80 min, during which time DA concentrations had declined 3-fold.

The temporal dissociation between AMPH-induced locomotion and DA release may be explained by the fact that most evidence (Kelly and Iversen, 1976; Sessions et al., 1980; Kehne et al., 1981; Swerdlow et al., 1986), including recent dialysis data (Sharp et al., 1987), implicate the mesolimbic DA system 
in the regulation of this behavior. However, our results also show that the stereotypy response does not closely relate to AMPH-induced DA release in the neostriatum. This temporal dissociation is particularly evident from a comparison of extracellular DA concentrations and the expression of oral behaviors produced by the administration of $5 \mathrm{mg} / \mathrm{kg}$ AMPH (Fig. 8). The mean maximal DA concentration (1400 nM) following this dose was observed during the $20-40 \mathrm{~min}$ interval, corresponding to the onset of oral stereotypies (Fig. 8). However, the magnitude of the stereotypy response was maintained in all animals throughout the subsequent $2 \mathrm{hr}$, whereas mean DA concentrations declined 7 -fold to $200 \mathrm{~nm}$. Similar temporal discrepancies are apparent for the stereotypy profiles produced by the other doses of AMPH as well. Thus, the extracellular DA concentration does not appear to be the sole determinant of AMPHinduced stereotypy.

We previously reported (Segal and Kuczenski, 1987a) that there is a wide range of individual differences in responsiveness to AMPH and that grouped data may obscure significant behavioral/neurochemical relationships. Therefore, one possible explanation for the dissociation between the behavioral and dopaminergic responses is that such relationships are apparent only when the comparisons are made for data from each animal separately. Our earlier results showed that the most extreme qualitative differences in response profile are produced by AMPH doses in the intermediate range $(1.5-2.0 \mathrm{mg} / \mathrm{kg})$. Animals injected, for example, with a dose of $2.0 \mathrm{mg} / \mathrm{kg}$ exhibit either a prolonged period of enhanced locomotion, generally associated with lower doses of AMPH, or a clearly multiphasic locomotor response, including a prolonged period of focused stereotypy, characteristic of higher doses of the drug. Likewise, this dose of AMPH produced a wide variation in the magnitude of DA response; i.e., peak DA concentrations, achieved during the 10 20 min interval, ranged from 438 to $1556 \mathrm{~nm}$. Therefore, as with the dose-response relationship, if DA release underlies these behavioral differences, the qualitative variations in behavior should correspond to different levels of DA release. However, our data showed (Fig. 10) that individual animals exhibiting contrasting response profiles (i.e., locomotor activation vs. a multiphasic pattern) can exhibit comparable levels of DA release. The absence of significant correlations between extracellular DA concentrations and dose-related changes in response profile suggests, therefore, that the transition from enhanced locomotion to focused stereotypies is not associated simply with quantitative differences in DA release in the region of striatum dialysed. Furthermore, although DA release increased in a dosedependent fashion (Fig. 6), there were no significant correlations between DA levels and behavior assessed for individual animals within each dose. These observations are consistent with results from our earlier studies using push-pull perfusion techniques (Segal and Kuczenski, 1987b; Kuczenski and Segal, 1988).

One possible explanation for the temporal dissociation is that the initial DA release is responsible for the initiation of neurochemical changes that more directly mediate the expression of stereotyped behaviors. For example, we have reported (Barnett and Kuczenski, 1986) a temporal and dose-related association between AMPH-induced oral stereotypies and a desensitization of striatal DA-sensitive adenylate cyclase, the D1 receptor. Thus, the pronounced increase in extracellular striatal DA associated with the administration of high AMPH doses appears to trigger DA receptor changes that may contribute to the continued expression of oral stereotypies in the absence of high levels of DA release. Such a persistent receptor alteration may underly the highly significant correlation $(R=0.98, p<$ 0.001 ) between DA concentration and oral behaviors during the late (160-200 min) interval of the $5 \mathrm{mg} / \mathrm{kg}$ response, in contrast to the absence of oral sterotypies during periods when lower doses induce similar or even higher levels of DA release. Similar biochemical events may also contribute to the transition from strictly enhanced locomotion to a multiphasic stereotyped response profile characteristic of intermediate doses of AMPH.

In contrast to our results, Sharp et al. (1987) reported a significant correlation between stereotyped repetitive movements and levels of DA in striatal dialysates, particularly when groups receiving either 0.5 or $2.0 \mathrm{mg} / \mathrm{kg}$ AMPH were combined. However, as we indicatcd previously, correlational analyses involving the degree of a specific behavior exhibited by animals that received different doses of AMPH may lead to misleading conclusions. For example, consistent with the report of Sharp et al., our data also yield a significant positive correlation for DA and repetitive head movements when animals that received 0.5 or $2.0 \mathrm{mg} / \mathrm{kg}$ AMPH are combined $(R=0.67, p<0.001)$, but the significance can be attributed to the biphasic distribution of data points, i.e., $0.5 \mathrm{mg} / \mathrm{kg}$ AMPH produced no repetitive movements and a lower increase in concentrations of DA compared with the effects of the $2.0 \mathrm{mg} / \mathrm{kg}$ dose. Similarly, our data reveal a significant negative correlation $(R=-0.68, p<0.001)$ when animals that received 2 or $5 \mathrm{mg} / \mathrm{kg}$ AMPH were combined. At the higher dose, oral sterotypies replaced repetitive movements as the predominant behavior and, therefore, the highest concentrations of DA were associated with the lowest levels of repetitive movements.

The absence of a close correspondence between extracellular DA concentrations and focused stereotypy suggests that modulating factors may significantly influence the AMPH response. In addition to the DA receptor changes discussed above, there is some evidence to suggest a role for 5-HT in modulating AMPHinduced stereotypy (Segal, 1976; Sloviter et al., 1978; Lucki and Harvey, 1979). Our results show that AMPH increases extracellular concentrations of 5-HT in striatum. The increase, while short-lived, was dose dependent and achieved significance following AMPH doses of $2 \mathrm{mg} / \mathrm{kg}$ and greater, suggesting that increases in extracellular 5-HT might be involved in the transition from locomotion to focused stereotypy. Within the 2.0 $\mathrm{mg} / \mathrm{kg}$ group, there was a significant negative correlation between 5-HT concentration and the time spent engaged in repetitive head movements (repetitive movements $0-40 \mathrm{~min}: R$ $=-0.61, p=0.045 ;$ total stereotypy: $R=-0.79, p-0.003$ ). Interestingly, the relationship persisted over the $40-120 \mathrm{~min}$ interval (repetitive movements: $R=-0.92, p=0.005$; stereotypy: $R=-0.98, p<0.001$ ), when animals continued to exhibit predominantly repetitive movements (Fig. 8), but when average 5-HT concentrations had returned to or fallen below baseline levels (Fig. 5). Thus, the tonic level of serotonergic neuronal function may play an important role in modulating the responsiveness to AMPH-induced DA release particularly with regard to the transition from locomotor activation to the multiphasic response pattern. The high correlation between baseline levels of 5-HT with the behavioral response to AMPH might reflect interanimal differences in tonic 5-HT release and consequent compensatory adjustments in receptor sensitivity. Thus, relatively low basal levels of 5-HT release might correspond to more sensitive 5-HT receptors, on which 5-HT released by AMPH may act to promote a more pronounced effect. This interpre- 
tation is consistent with the alleged complementary relationship between striatal DA and 5-HT (Rebec et al., 1981; Rebec and Curtis, 1983).

Our results suggest that the perseverative quality of the AMPH response may be influenced by various striatal mechanisms, including levels of both DA and 5-HT neurotransmitter release, as well as the state of their respective receptors. In addition, there is ample evidence to suggest a role for the mesolimbicmesocortical DA system in the behavioral effects of stimulants (Kelly and Iversen, 1976; Sessions et al., 1980; Kehne et al., 1981; Swerdlow et al., 1986), and we have previously argued (Segal and Kuczenski, 1987a) that a balance between this pathway and the nigrostriatal systems may contribute to dose-related and individual differences in responsiveness to AMPH. The evaluation of neurochemical changes in multiple nuclei concurrent with thorough characterization of the behavioral response profile will be required to further elucidate the relative contribution of the various neurotransmitter systems and mechanisms to the expression of AMPH-induced behaviors.

\section{References}

Baraban, J. M., R. Y. Wang, and G. K. Aghajanian (1978) Reserpine suppression of dorsal raphe neuronal firing: Mediation by adrenergic system. Eur. J. Pharmacol. 52: 27-36.

Barnett, J. V., and R. Kuczenski (1986) Desensitization of rat striatal dopamine-stimulated adenylate cyclase after acute amphetamine administration. J. Pharmacol. Exp. Ther. 237: 820-825.

Bcckcr, J. B., F. A. Adams, and T. E. Robinson (1988) Intraventricular microdialysis: A new method for determining monoamine metabolite concentrations in the cerebrospinal fluid of freely moving rats. J. Neurosci. Methods 24: 259-269.

Braestrup, C. (1977) Biochemical differentiation of amphetamine vs. methylphenidate and nomifensine in rats. J. Pharm. Pharmacol. 29: $463-472$.

Breese, G., B. R. Cooper, and R. A. Mueller (1974) Evidence for the involvement of 5-hydroxytryptamine in the actions of amphetamine. Br. J. Pharmacol. 52: 307-314.

Brodie, B. B., and P. A. Shore (1957) A concept for a role of serotonin and norepinephrine as chemical mediators in the brain. Ann. NY Acad. Sci. 66: 631-642.

Costall, B., and R. J. Naylor (1974) Stereotyped and circling behavior induced by dopaminergic agonists after lesions of the midbrain raphe nuclei. Eur. J. Pharmacol. 29: 206-222.

Creese, I., and S. D. Iversen (1974) The role of forebrain dopamine systems in amphetamine-induced stereotypy in the adult rat following neonatal treatment with 6-hydroxydopamine. Psychopharmacology 39: 345-357.

Di Giulio, A. M., A. Groppetti, F. Cattabeni, C. L. Galli, A. Maggi, S. Algeri, and F. Ponzio (1978) Significance of dopamine metabolites in the evaluation of drugs acting on dopaminergic neurons. Eur. J. Pharmacol. 52: 201-207.

Foote, W., M. Sheard, and G. K. Aghajanian (1969) Comparison of LSD and amphetamine on midbrain raphe units. Nature 222: 567569.

Gallager, D. W., and G. K. Aghajanian (1976) Effect of antipsychotic drugs on the firing rate of dorsal raphe cells. I. Role of adrenergic system. Eur. J. Pharmacol. 39: 341-355.

Geyer, M. A., W. J. Dawsey, and A. J. Mandell (1975) Differential effects of caffeine, D-amphetamine and methylphenidate on individual raphe cell fluorescence: A microspectro-fluorimetric demonstration. Brain Res. 106: 241-256.

Grahame-Smith, D. G. (1971) Studies in vivo on the relationship between brain tryptophan, brain 5-HT synthesis and hyperactivity in rats treated with a monoamine oxidase inhibitor and L-tryptophan. J. Neurochem. 18: 1053-1066.

Hammond, D. L., G. M. Tyce, and T. L. Yaksh (1983) Drug-induced alterations in the efflux of 5-hydroxytryptamine and of 5-hydroxyindoleacetic acid into superfusates of the rat spinal cord. Eur. J. Pharmacol. 87: 441-448.
Imperato, A., and G. Di Chiara (1984) Trans-striatal dialysis coupled to reverse phase high performance liquid chromatography with electrochemical detection: A new method for the study of the in vivo release of endogenous dopamine and metabolites. J. Neurosci. 4: $966-$ 977.

Imperato, A., and G. Di Chiara (1985) Dopamine release and metabolism in awake rats after systemic neuroleptics as studied by transstriatal dialysis. J. Neurosci. 5: 297-306.

Imperato, A., G. Tanda, R. Frau, and G. Di Chiara (1988) Pharmacological profile of dopamine receptor agonists as studied by brain dialysis in behaving rats. J. Pharmacol. Exp. Ther. 245: 257-264.

Kehne, J. H., W. W. Sant, and C. A. Sorenson (1981) The effects of radiofrequency lesions of the nucleus accumbens on d-aphetamineinduced locomotor and rearing behavior in rats. Psychopharmacology 75: 363-367.

Kelly, P. H. (1977) Drug induced motor behavior. In Handbook of Psychopharmacology, Vol. 8, L. L. Iverson, S. D. Iverson, and S. H. Snyder, eds., pp. 295-331, Plenum, New York.

Kelly, P., and S. D. Iversen (1976) Selective 60HDA-induced destruction of mesolimbic dopamine neurons: Abolition of psychostimulant-induced locomotor activities in rats. Eur. J. Pharmacol, 40: 4556.

Kelly, P., P. Seviour, and S. D. Iversen (1975) Amphetamine and apomorphine responses in the rat following 6-OHDA lesions of the nucleus accumbens septi and corpus striatum. Brain Res. 94: 507522.

Kuczenski, R. (1980) Amphetamine-haloperidol interactions on striatal and mesolimbic tyrosine hydroxylase activity and dopamine metabolism. J. Pharmacol. Exp. Ther. 215: 135-142.

Kuczenski, R. (1983) Biochemical actions of amphetamine and other stimulants. In Stimulants: Neurochemical, Behavioral, and Clinical Perspectives, I. Creese, ed., pp. 31-61, Raven, New York.

Kuczenski, R. (1986) Dose response for amphetamine-induced changes in dopamine levels in push-pull perfusates of rat striatum. J. Neurochem. 46: 1605-1611.

Kuczenski, R., and D. S. Segal (1988) Psychomotor stimulant-induced sensitization: Behavioral and neurochemical correlates. In Sensitization in the Nervous System, P. Kalivas and T. Barnes, eds., pp. 175-205, Telford, Caldwell, NJ.

Kuczenski, R., D. S. Segal, N. J. Leith, and C. D. Applegate (1987) Effects of amphetamine, methylphenidate, and apomorphine on regional brain serotonin and 5-hydroxyindole acetic acid. Psychopharmacology (Berl.) 93: 329-335.

Kuhn, D. M., W. A. Wolf, and M. B. H. Youdim (1985) Serotonin release in vivo from a cytoplasmic pool: Studies on the serotonin behavioral syndrome in reserpinized rats. $\mathrm{Br}$. J. Pharmacol. 84: 121129.

Lucki, I., and J. A. Harvey (1979) Increased sensitivity to d- and l-amphetamine action after midbrain raphe lesions as measured by locomotor activity. Neuropharmacology 18: 243-249.

Mabry, P. D., and B. A. Campbell (1973) Serotonergic inhibition of catecholamine-induced behavioral arousal. Brain Res. 49: 381-391.

Neill, D. B., I. D. Grant, and S. P. Grossman (1972) Selective potentiation of locomotor effects of amphetamine by midbrain raphe lesions. Physiol. Behav. 9: 655-657.

Paxinos, G., and C. Watson (1986) The Rat Brain in Stereotaxic Coordinates, Academic, Sydney.

Rebec, G. V., and S. D. Curtis (1983) Reciprocal changes in the firing rate of neostriatal and dorsal raphe neurons following local infusions or systemic injections of d-amphetamine. J. Neurosci. 3: 2240-2250.

Rebec, G. V., K. D. Alloway, and S. D. Curtis (1981) Apparent serotonergic modulation of the dose-dependent biphasic response of neostriatal neurons produced by D-amphetamine. Brain Res. 210: $277-$ 289.

Robinson, T. E., and I. Q. Whishaw (1988) Normalization of extracellular dopamine in striatum following recovery from a partial unilateral 6-OHDA lesion of the substantia nigra: A microdialysis study in freely moving rats. Brain Res. 450: 209-224.

Segal, D. S. (1976) Differential effects of para-chlorophenylalanine on amphetamine-induced locomotion and stereotypy. Brain Res. 116 $267-276$

Segal, D. S., and M. A. Geyer (1985) Animal models of psychopathology. In Psychiatry, Vol. 3, J. O. Cavenar, Jr., ed., Lippincott, Philadelphia.

Segal, D. S., and R. Kuczenski (1987a) Individual differences in re- 
sponsiveness to single and repeated amphetamine administration: Behavioral characteristics and neurochemical correlates. J. Pharmacol. Exp. Ther. 242: 917-926.

Segal, D. S., and R. Kuczenski (1987b) Behavioral and neurochemical characteristics of stimulant-induced augmentation. Psychopharmacol. Bull. 23: 417-424.

Segal, D. S., and M. Schuckit (1983) Animal models of stimulantinduced psychosis. In Stimulants: Neurochemical, Behavioral and Clinical Perspectives, I. Creese, ed., pp. 131-167, Raven, New York.

Sessions, G., J. Meyerhoff, G. J. Kant, and G. F. Koob (1980) Effects of lesions of the ventral medial tegmentum on locomotor activity, biogenic amines and response to amphetamine in rats. Pharmacol. Biochem. Behav. 12: 603-608.

Shannon, N. J., J. W. Gunnet, and K. E. Moore (1986) A comparison of biochemical indices of 5-hydroxytryptaminergic neuronal activity following electrical stimulation of the dorsal raphe nucleus. J. Neurochem. 47: 958-965.

Sharp, T., T. Zetterstrom, T. Ljungberg, and U. Ungerstedt (1986) Effect of sulpiride on amphetamine-induced behaviour in relation to changes in striatal dopamine release in vivo. Eur. J. Pharmacol. 129: 411-415.

Sharp, T., T. Zetterstrom, T. Ljungberg, and U. Ungerstedt (1987) A direct comparison of amphetamine-induced behaviours and regional brain dopamine release in the rat using intracerebral dialysis. Brain Res. 401: 322-330.

Sloviter, R. S., E. G. Drust, and J. D. Connor (1978) Evidence that serotonin mediates some behavioral effects of amphetamine. Exp. Ther. 206: 348-352.

Swerdlow, N. R., F. J. Vaccarino, M. Amalric, and G. F. Koob (1986) The neural substrates for the motor-activating properties of psychostimulants: A review of recent findings. Pharmacol. Biochem. Behav. 25: 233-248.
Westerink, B. H. C. (1985) Sequence and significance of dopamine metabolism in the rat brain. Neurochem. Int. 7: 221-227.

Westerink, B. H., and S. J. Spaan (1982) On the significance of endogenous 3-methoxytyramine for the effects of centrally acting drugs on dopamine release in the rat brain. J. Neurochem. 38: 680-688.

Westerink, B. H., and M. H. Tuinte (1986) Chronic use of intracerebral dialysis for the in vivo measurement of 3,4-dihydroxyphenylethylamine and its metabolite 3,4-dihydroxyphenylacetic acid. J. Neurochem. 46: 181-185.

Westerink, B. H., G. Damsma, J. B. de Vries, and H. Koning (1987) Dopamine re-uptake inhibitors show inconsistent effects on the in vivo release of dopamine as measured by intracerebral dialysis in the rat. Eur. J. Pharmacol. 135: 123-128.

Westerink, B. H., H. M. Hofsteede, G. Damsma, and J. B. de Vries (1988) The significance of extracellular calcium for the release of dopamine, acetylcholine and amino acids in conscious rats, evaluated by brain microdialysis. Naunyn Schmiedbergs Arch. Pharmacol. 337. 373-378.

Zetterstrom, T., T. Sharp, C. A. Marsden, and U. Ungerstedt (1983) In vivo measurement of dopamine and its metabolites by intracerebral dialysis: Changes after d-amphetamine. J. Neurochem. 41: 17691773.

Zetterstrom, T., T. Sharp, and U. Ungerstedt (1984) Effect of neuroleptic drugs on striatal dopamine release and metabolism in the awake rat studied by intracerebral dialysis. Eur. J. Pharmacol. 106: 27-37.

Zetterstrom, T., T. Sharp, and U. Ungerstedt (1986) Further evaluation of the mechanism by which amphetamine reduces striatal dopamine metabolism: A brain dialysis study. Eur. J. Pharmacol. 132: $1-9$. 